\title{
Effect of electrical stimulation of the cranial tibial muscle after end-to-side neurorrhaphy of the peroneal nerve in rats ${ }^{1}$
}

\author{
Fábio Oliveira Maciel, Fausto Viterbo"II, Laís de Fátima Chuvukian Chinaque ${ }^{\mathrm{II}}$, Bárbara Moraes Souza ${ }^{\mathrm{IV}}$ \\ IAssistant Professor of Physiotherapy, Institute of Health and Biotechnology, Federal University of Amazonas (UFAM), Brazil. Main author. Conception, \\ design, intellectual and scientific content of the study; acquisition and interpretation of data, statistical analysis, manuscript writing.

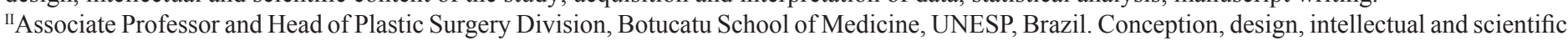 \\ content of the study; interpretation of data, critical revision.

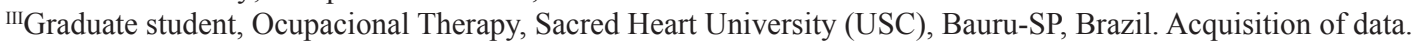 \\ ${ }^{\text {IV }}$ Graduate student, Biomedicine, UNESP, Botucatu-SP, Brazil. Acquisition of data.
}

\begin{abstract}
PURPOSE: To investigate the efficiency of electrical stimulation in the muscle maintenance and nerve regeneration after end-to-side neurorrhaphy (ESN).

METHODS: Sixty male Wistar rats (Rattus norvegicus) were divided into four experimental groups. Control group (Control), Denervated Group (Denervated); Group with End-to-side neurorrhaphy (ESN); Group with End-to-side neurorrhaphy and electrical stimulation $(\mathrm{ESN}+\mathrm{ES})$. We perform electrical stimulation in rats after they had undergone muscle reinnervation by ESN. We collected morphometric and functional data.

RESULTS: When comparing the mass of the treated side of cranial tibial muscle (CTM) and that of normal side of CTM, the group ESN + ES (26.12\%) exhibited lower mass loss than that of group ESN (37.23\%). The peroneal functional index showed that group ESN + ES equaled that of the Control group and showed an evolution of $60.5 \%$ while group ESN showed an evolution of $9.5 \%$. In measuring maximum strength of CTM, the group ES + ESN outperformed group ESN. The muscle and nerve morphometry showed superiority of group ES+ESN over ESN group in all parameters.

CONCLUSION: Electrical stimulation is an effective means of maintaining functional muscle and nerve regeneration after end-to-side neurorrhaphy.
\end{abstract}

Key words: Suture Techniques. Electric Stimulation. Muscle Denervation. Peroneal Nerve. Rats. 


\section{Introduction}

The peripheral nerves disorders lead to different types and degrees of injuries ${ }^{1}$. Lesions in peripheral nerves usually cause changes in the structure, metabolism and physiological activity of the neuronal cell body, and may stop the innervation of organs distal to the lesion, in the case of motor neuron, the organ committed is the muscle ${ }^{2,3}$.

For the treatment of peripheral nerve injuries, microsurgery has advanced greatly and thus plays a key role in the prognosis of patients suffering from this disorder. One of the landmark advanced occurred in 1992 when Viterbo et al. ${ }^{4}$ proposed end-to-side neurorrhaphy (ESN) that would not contribute to donor nerve damage and also without the removal of the epineurium ${ }^{5}$. In an experimental study in rats, Viterbo et $a l .{ }^{4}$ performed a section of the peroneal nerve, which innervates the cranial tibial muscle (CTM), and its distal stump was sutured to the lateral surface of the intact tibial nerve. Muscle reinnervation was hence achieved without injuring the donor nerve. This technique has brought great contribution, because from then on, any nerve can be used as a donor nerve without harming itself or any of the structures innervated by it. Several experimental and clinical studies has validated the study of Viterbo ${ }^{5-7}$. Use of ESN has been indicated in clinical situations in which the proximal stump of injured nerve is not available ${ }^{8}$.

However, even with the advances in microsurgery, we still have not been able to achieve full motor recovery in the repair of the damaged nerve, because complete recovery of motor function is dependant on axon regeneration and the process of atrophy of the muscles innervated by the nerve occurs during axon regeneration, a fact that promotes functional damage to the muscle ${ }^{9,10}$.

Electrical stimulation (ES) to promote regeneration, although controversial ${ }^{11-13}$, became a topic of study in functional muscle recovery, and may be used as a method of preventing muscle atrophy resulting from a period of muscle inactivity regardless if caused by denervation or not ${ }^{9}$.

Authors, such as Tagami et al. ${ }^{14}$ observed that the daily application of electrical stimulation in rats is beneficial for axonal regeneration and does not contribute to functional impairment, unlike some authors who have cited harmful effects of electrical stimulation, causing contractures and spasms ${ }^{11-13}$.

ES to increase the performance capability of skeletal muscle is demonstrated in experimental and clinical studies ${ }^{15-21}$. They are able to increase the activity of oxidative enzymes in muscle fibers, enhance muscle regeneration and prevent skeletal muscle atrophy ${ }^{9}$. In addition to the metabolic effects, ES also helps in minimizing the effects of immobilization, minimizing the reduction of cross-sectional area, interstitial fibrosis and deficiency of blood supply ${ }^{22}$. ES promotes increased effectiveness of contractile muscle fibers, enabling thus the dynamics of uptake via GLUT-4, glucose metabolism and activity of cellular metabolic pathways $^{23-28}$.

ESN allows the passage of nerve impulses through the reinnervated region ${ }^{29,30}$, however, the functional demand of a patient goes beyond the passage of the stimulus by the junction between the donor and the recipient nerve. A healthy muscle must have the innate ability to produce tension during contraction to produce movement. For this reason the objective of this study was to analyze the efficiency of electrical stimulation in the maintenance of muscle and nerve regeneration after end-to-side neurorrhaphy.

\section{Methods}

Research approved by the Ethics Committee (CEEA. Protocol n. 746) of FMB/UNESP and the study was conducted in accordance with the ethical principles.

Sixty male Wistar rats (Rattus norvegicus) were used, weighing an average of $261.87 \mathrm{~g}(+/-28.39)$. The rats were randomly divided into four experimental groups. The surgeries were performed according to the group in which the rats were divided. In the Control group (Control) with ten rats, the peroneal nerve was dissected, however, but without section or neurorrhaphy (Figure 1A). Denervated group (Denervated) with ten rats, the peroneal nerve was cut and their stumps were inverted 180 degrees and fixed to underlying muscles, and the proximal stump was transfixed by an incision in the adjacent musculature and sutured in the subcutaneous plane to prevent motor contamination (Figure 1B). End-to-side neurorrhaphy group (ESN) with 20 rats, the peroneal nerve was transected and its proximal stump bent 100 degrees medially, and transfixed by an incision in the adjacent musculature and sutured in the subcutaneous plane preventing spontaneous regeneration. The distal stump of the peroneal nerve was bent approximately $80^{\circ}$ and sutured laterally to the tibial nerve (Figure 1C). Group End-to-side neurorrhaphy and electrical stimulation $(\mathrm{ESN}+\mathrm{ES})$ with 20 rats, the rats underwent the similar procedure as group ESN, however, during recovery, they received electrical stimulation in CTM as adjunct treatment (Figure 1D). 

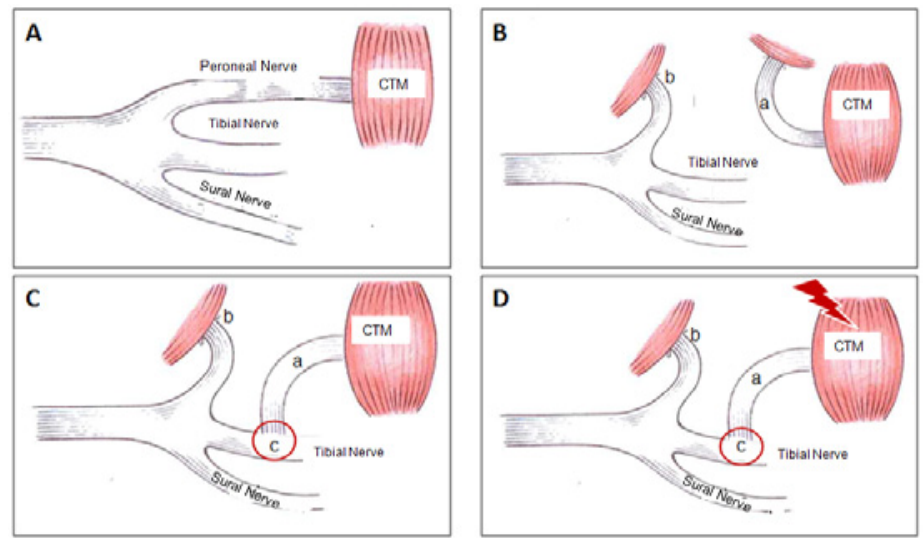

FIGURE 1 - Indicates surgical procedures. A) Control group. B) Denervated group. C) ESN group. D) ESN+ES group. CTM) Cranial Tibial Muscle. a) Peroneal nerve distal stump. b) Peroneal nerve proximal stump. c) End-to-side neurorrhaphy. Ray) Indicates CTM treatment with ES.

The rats were anesthetized with ketamine $(70 \mathrm{mg} / \mathrm{kg}$ ip) and xilasine $(30 \mathrm{mg} / \mathrm{kg}$ ip) administered intramuscularly. The dorsal lateral aspect of one hind limb, suffered incision of 2 to $3 \mathrm{~cm}$ along the longest axis of the limb, affecting skin and subcutaneous tissue with subsequent expansion of the muscles. The sciatic nerve, common peroneal, tibial and sural nerve were dissected. Thereafter, the procedure was performed according to the experimental group (Figure 2).
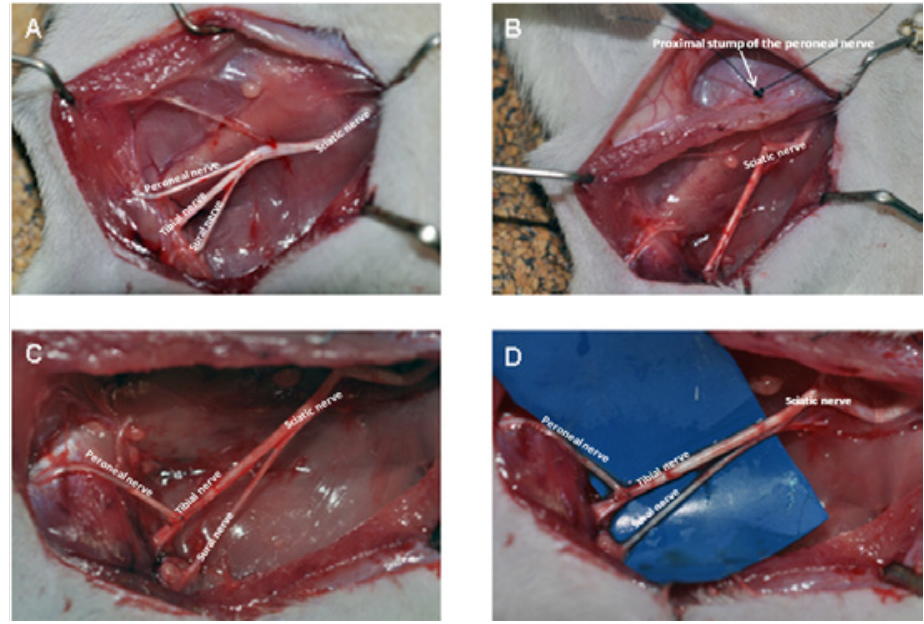

FIGURE 2 - Indicates the surgical procedure. A) Exposure of the sciatic nerve and its branches, the peroneal nerve, tibial nerve and sural nerve. B) Proximal stump of the peroneal nerve transfixing adjacent muscles and being sutured on it superficial side. C) Peroneal ESN on tibial nerve lateral. D) Another view of ESN.

The surgeries were performed with the surgical microscope MU-M19 DF Vasconcelos (Sao Paulo, SP) with magnification of 10 and 16 times. The neurorrhaphies were performed with 10-0 monofilament nylon cylindrical and circular shaped needle, without an epineurium window and with two simple bites. After the procedure, the incision was closed in layers with simple stitches using 4-0 nylon suture for muscle and skin.

The rats were kept in the appropriate boxes, containing five animals each in controlled temperature $\left(25 \pm 2^{\circ} \mathrm{C}\right)$, light-dark cycle of 12 hours, with food and water ad libitum until time of sacrifice which occurred after 180 days.

Electrical stimulation began five days after surgery. The rats in group ESN+ES underwent three sessions per week for 180 days. They received applications of electrical stimulation to the cranial tibial muscle with alternating current using $1 \mathrm{kHz}$ frequency, modulation at $10 \mathrm{~Hz}$, with duration of $2 \mathrm{~ms}$ (modulation), ON Time 10 seconds, OFF Time 20 seconds, during 10 minutes. The initial current was $8 \mathrm{~mA}$ and after five minutes, was increased to $12 \mathrm{~mA}$ to avoid the effect of tissue accommodation. Electrical stimulator used was Neurodyn 10 Channels Ibramed Company (Amparo / SP).

The rats were stimulated without anesthesia; a special metal capsule was developed for this purpose with a posterior opening for the tail and two side openings for fixing the hindlimbs. After this immobilization, the electrodes were fixed (Figure 3). Ten capsules were used simultaneously to optimize stimulation time.
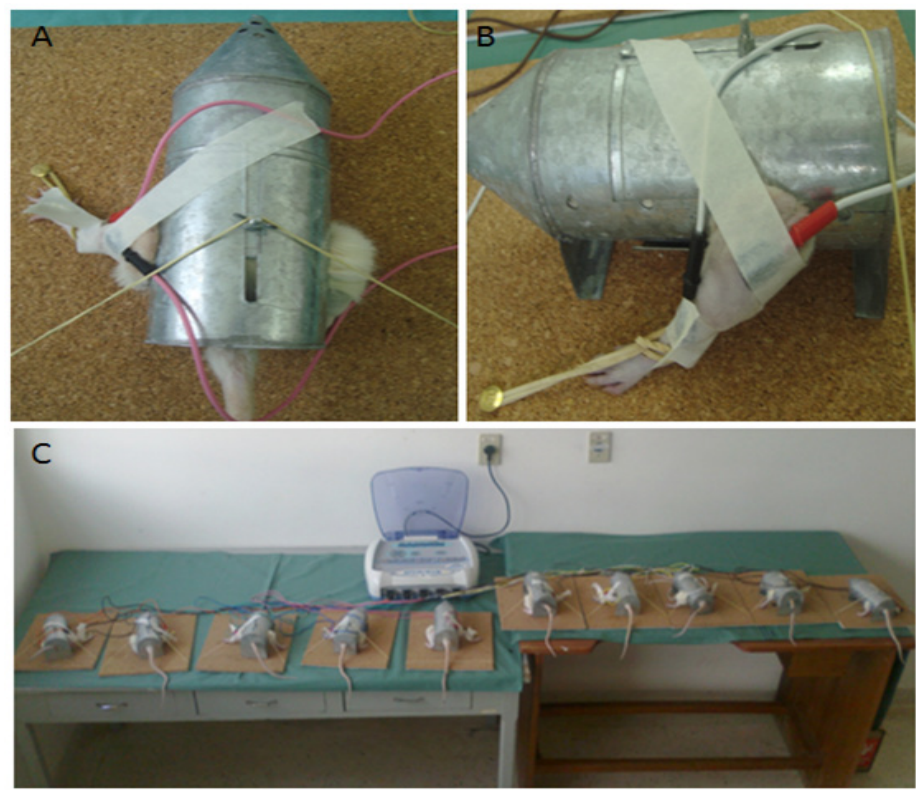

FIGURE 3 - Electrical Stimulation. A) Positioning of rats in capsule stimulation. B) Another view of the rats in the capsule. C) Rats receiving stimulation at the same time.

Tests

Walking track analysis (WTA)

Animals were tested for walking track analysis every 30 
days. The peroneal function index (PFI) was used ${ }^{31}$.

\section{Electrophysiological test}

For electrophysiological testing, the temperature was maintained around $25^{\circ} \mathrm{C}$. The compound action potential was recorded by needle electrodes active and reference. The reference electrode was placed in rats cranial tibial muscle tendon, the active electrode in cranial tibial muscle belly, and the dispersive electrode, introduced in a location away from the test region.

The electrodes recorded the amplitude and latency of the muscle action potential. The pulses were generated by a bipolar electrode specially developed for this purpose, whose cathode and anode were $2 \mathrm{~mm}$ apart, which was positioned directly over the sciatic nerve prior to neurorrhaphy region, and the stimulation was made proximal to the neurorrhaphy, enabling the spread of electrical impulses through them. The frequency of the stimulus was set at $1 \mathrm{pps}$ and $100 \mathrm{~ms}$ in duration. The stimulus intensity used, constant in all animals was 5.1 volts.

\section{$\underline{\text { CTM Force contraction }}$}

After electrophysiological testing, the distal tendon of the cranial tibial muscle was sectioned and connected to a force transducer FT03 Grass Technologies Company, An Astro-Med, Inc. (West Warwick, RI) using nylon suture with 4-0. The ideal length of the muscle was maintained by a pre-tensioning load of $0.18 \mathrm{~N}$ and was reset between tests. This preload value was determined during calibration of the device.

Electrical stimulation was generated directly from CTM exposed. The test consisted of muscle contraction in three sequential applications of one second of duration with the same specifications as the current power used for the treatment of group $\mathrm{ESN}+\mathrm{ES}$. Muscle tension was readjusted between measurements. The tetanic contraction test was performed with $100 \mathrm{~mA}$ and frequency of $100 \mathrm{~Hz}$.

\section{Collection of histological pieces and sacrifice}

After completion of muscle strength testing, the rats received a lethal dose of sodium pentobarbital, administered intraperitoneally, and proceeded to collect the peroneal nerve segments and cranial tibial muscles.

The segment called "N1" represents the cross section of the distal stump of the peroneal nerve.

The cranial tibial muscles were removed, weighed and kept immersed in liquid nitrogen $\left(-196^{\circ} \mathrm{C}\right)$ and subjected to cross-sections of 7 micrometers. The sections were performed in the central region, across the major axis of the muscle. Sections were stained with hematoxylin - eosin (HE). The images were captured and digitized by an Aperio ScanScope Image Scanner (Vista, CA) and analyzed by measures of area, perimeter and minimum diameter of muscle fibers. Measurements were made of semi-automatic mode using Sigma Pro Image Analysis software, version 5 from Jandel Scientific (San Jose, CA).

The N1 segment of nerve was fixed and kept in solution Karnovisk and refrigerated at $4^{\circ} \mathrm{C}$ until histological processing. Transverse cuts were made semi-fine $(0.5 \mu \mathrm{M})$ in microtome. The staining was performed manually by razor blade, with $1 \%$ toluidine blue for 5 minutes. The scanned images were saved and analyzed through measures of minimum diameter, fiber number and area and thickness of the myelin sheath.

\section{Statistical analysis}

When comparing the groups, was used analysis of variance (ANOVA) followed by Tukey test when significant differences was detected. When the distribution of the data presented was not in normal range, the analysis of variance on ranks was used, Kruskal-Wallis test followed by Dunn's method, when difference was noted. For comparison between mass of experimental and normal CTM was utilized paired t test. In all tests, was used a significance level of $p<0.05$. The program used for the analysis was SigmaStat 3.5 Software Jandel Scientific (San Jose, CA).

\section{Results}

The experimental CTM mass compared with normal CTM mass in each group showed no difference between experimental and normal sides in the control group. In other groups, the normal side was always higher than the experimental side, however, the loss of muscle mass for group ESN+ES (26.12\%) was lower than the loss of muscle mass for group ESN (37.23\%) (Table 1). 
Effect of electrical stimulation of the cranial tibial muscle after end-to-side neurorrhaphy of the peroneal nerve in rats

TABLE 1 - Mean and standard deviation of the CTM and percentage mass loss of CTM experimental compared to normal (g).

\begin{tabular}{ccccccccc}
\hline & \multicolumn{2}{c}{ Control } & \multicolumn{2}{c}{ Denervated } & \multicolumn{2}{c}{ ESN } & \multicolumn{2}{c}{ ESN+ES } \\
& Normal & Experimental & Normal & Experimental & Normal & Experimental & Normal & Experimental \\
\hline Mean & 0.828 & 0.914 & 0.859 & 0.172 & 0.803 & 0.504 & 0.804 & 0.594 \\
SD & 0.147 & 0.177 & 0.135 & 0.0499 & 0.165 & 0.211 & 0.148 & 0.152 \\
\hline Loss \% & \multicolumn{2}{c|}{-10.39} & \multicolumn{2}{c|}{79.98} & & 37.23 & & 26.12 \\
\hline
\end{tabular}

The peroneal functional index for 180 days after surgery showed group ESN+ES was the only one to match the control group. The medians $(25 \% / 75 \%)$ for this measure were: Control) -20.0 (-37.4 / 1.3); Denervated) -127.0 (-169.3 / -110.4); ESN) -74.5 (-180.3 / -0.3), ESN+ES) -29.9 (-147.9 / -11.3) (Figure 4A).

Figure 4B represents the variation of the peroneal functional index between 30 and 180 days postoperatively. The ESN+ES group improved $60.5 \%$ while the ESN group improved $9.5 \%$ only.

Figure $4 \mathrm{C}$ represents the maximum force contraction of experimental CTM between groups. The results showed ESN+ES group higher than ESN Group. Median (25\% / 75\%): Control) 0.870 (0.705 / 0.970); Denervated) 0.290 (0.268/ 0.328); ESN) 0.765 (0.620 / 0.890) ESN+ES) 0.890 (0.810 / 0.990).
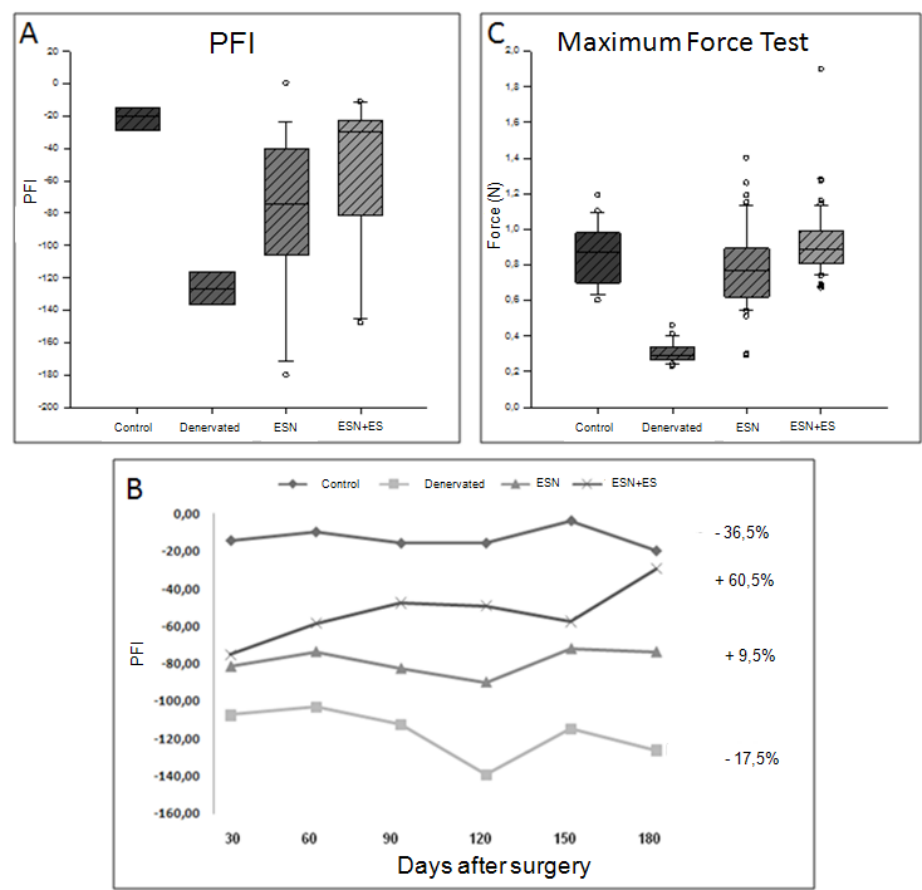

FIGURE 4 - Walking test analysis and maximum force contraction. A) Box Plot to PFI 180 days postoperatively. Kruskal-Wallis followed by Dunn's method. Control $=\mathrm{ESN}+\mathrm{ES}>$ Denervated; Control $>\mathrm{ESN}=$ Denervated; $\mathrm{ESN}+\mathrm{ES}=\mathrm{ESN}(\mathrm{P}<0.001)$. B) Evolution of the peroneal functional index between 30 and 180 days postoperatively. C) Box plot of maximum force contraction of experimental CTM (N). Kruskal-Wallis followed by Dunn's method. ESN+ES = Control $>$ Denervated; ESN+ES $>$ ESN $>$ Denervated; Control $=$ ESN $(p<0.001)$.
The electrophysiological test for latency and amplitude showed equivalence between groups. For latency the median (25\% / 75\%) was: Control) 1.84 (1.62/1.98); ESN) 1.6 (1.5/ 2.6); ESN+ES) 1.9 (1.6 / 2.3). Kruskal-Wallis $(\mathrm{p}=0.803)$. For amplitude the median (25\% / 75\%) was: Control) 13.1 (8.1 / 27.6); ESN) 6.45 (4.2 / 12.9); ESN+ES) 11.03 (3.1 / 17.9). KruskalWallis $(\mathrm{p}=0.150)$.

Figure 5A represents the perimeter of experimental cranial tibial muscle fiber. The results showed Control group rather than other groups and ESN+ES group superior to ESN group. Median (25\% / 75\%): Control) 273.32 (228.3 / 321.7); Denervated) 96.25 (76.6 / 126.6); ESN) 189.38 (144.3 / 217.8), ESN+ES) 224.88 (201.9 / 242.3).

Figure 5B represents the minimum diameter of experimental cranial tibial muscle fibers. For this parameter, the ESN+ES group is higher than ESN group, but lower than control group. Median (25\% / 75\%): Control) 58.05 (48.6 / 68.2); Denervated) 21.7 (17.2 / 26.6); ESN) 41.92 (33.5 / 48.5); ESN+ES) 49.35 (46.2 / 54.9).

Figure $5 \mathrm{C}$ represents the area of experimental cranial tibial muscle fiber. The ESN+ES group was superior to ESN group, but still not reaching the control group. Median $(25 \% /$ 75\%): Control) 4280.27 (2894.8 / 5463.9); Denervated) 562.16 (352.1 / 910.1); ESN) 2104.34 (1299.8 / 2748.9), ESN+ES) $2882.81(2437.9$ / 3361.5). 

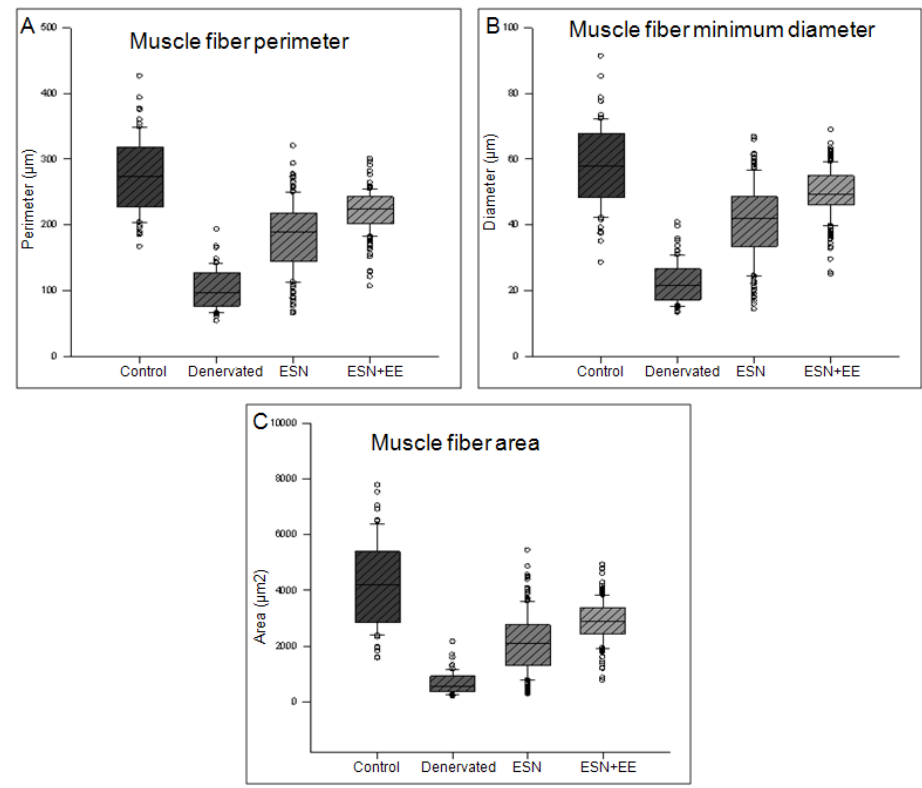

FIGURE 5 - Muscular Morphometrics. A) Box plot for experimental CTM fibers perimeter $(\mu \mathrm{m})$. Kruskal-Wallis followed by Dunn's method. Control $>$ ESN+ES $>$ ESN $>$ Denervated $(\mathrm{p}<0.001)$. B) Box plot for experimental CTM fibers minimum diameter $(\mu \mathrm{m})$. Kruskal-Wallis test followed by Dunn's method. Control $>$ ESN+ES $>$ ESN $>$ Denervated ( $p$ $<0.001)$. C) Box plot for experimental CTM fibers area $\left(\mu \mathrm{m}^{2}\right)$. KruskalWallis test followed by Dunn's method. Control $>$ ESN+ES $>$ ESN $>$ Denervated $(\mathrm{p}<0.001)$.

Figure 6A represents the number of nerve fibers in each group for N1 segment. The Control group is superior to others and ESN+ES group is presenting a good result, higher than ESN group. Mean (SD): Control) 1397.06 (331) Denervated) 0.0 (0.0); ESN) 577.67 (332.6); ESN+ES) 952.8 (229.5).

Figure $6 \mathrm{~B}$ represents the minimum diameter of nerve fibers in each group for N1 segment. Remained the same pattern of results presented in the above parameters with Control higher than others groups and ESN+ES group above the ESN group. Mean (SD): Control) 10.57 (1.8); Denervated) 0.0 (0.0); ESN) 7.19 (1.4); ESN+ES) 8.42 (1.6).

Figure 6C represents nerve fibers myelin sheath area of N1 segment in each group. The ESN+ES group was superior to ESN group. Median (25\% / 75\%): Control) 91.82 (78.8 / 104.8); Denervated) 0.0 (0.0/0.0); ESN) 40.86 (32/45, 2); ESN+ES) 58.39 (35.5 / 67.6).

Figure 6D represents nerve fibers myelin sheath thickness of N1 segment in each group. The results shows ESN+ES group above ESN Group. Median (25\% / 75\%): Control) 2.83 (2.5 / 3.1); Denervated) 0.0 (0.0/ 0.0); ESN) 1.92 (1.8/ 2.0); ESN+ES) 2.48 (2.1/2.8).

Figure 6A represents the number of nerve fibers in each group for N1 segment. The Control group is superior to others and $\mathrm{ESN}+\mathrm{ES}$ group is presenting a good result, higher than ESN group. Mean (SD): Control) 1397.06 (331) Denervated) 0.0 (0.0); ESN) 577.67 (332.6); ESN+ES) 952.8 (229.5).

Figure $6 \mathrm{~B}$ represents the minimum diameter of nerve fibers in each group for N1 segment. Remained the same pattern of results presented in the above parameters with Control higher than others groups and ESN+ES group above the ESN group. Mean (SD): Control) 10.57 (1.8); Denervated) 0.0 (0.0); ESN) 7.19 (1.4); ESN+ES) 8.42 (1.6).

Figure $6 \mathrm{C}$ represents nerve fibers myelin sheath area of $\mathrm{N} 1$ segment in each group. The ESN+ES group was superior to ESN group. Median (25\% / 75\%): Control) 91.82 (78.8 / 104.8); Denervated) 0.0 (0.0/ 0.0); ESN) 40.86 (32/45, 2); ESN+ES) 58.39 (35.5 / 67.6).

Figure $6 \mathrm{D}$ represents nerve fibers myelin sheath thickness of N1 segment in each group. The results shows ESN+ES group above ESN Group. Median (25\% / 75\%): Control) 2.83 (2.5 / 3.1); Denervated) 0.0 (0.0 / 0.0); ESN) 1.92 (1.8/ 2.0); ESN+ES) 2.48 $(2.1 / 2.8)$.
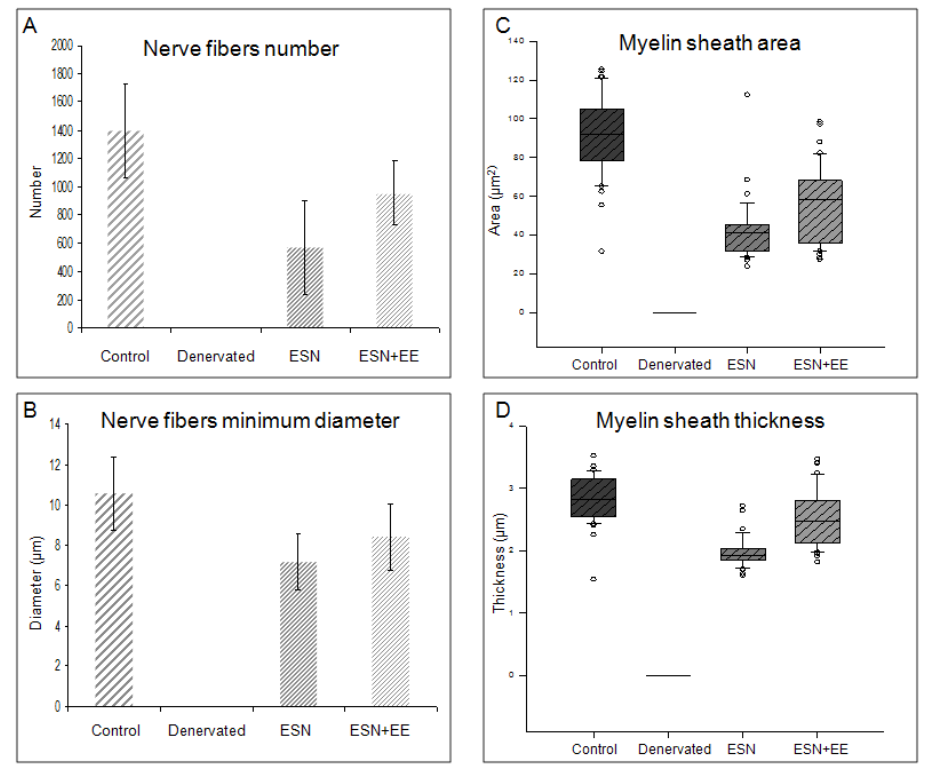

FIGURE 6 - Nerve Morphometrics to N1 segmente. A) Nerve fibers number. ANOVA followed by Tukey test. Control $>$ ESN+ES $>$ ESN $>$ Denervated $(\mathrm{p}<0.001)$. B) Nerve fibers minimum diameter $(\mu \mathrm{m})$. ANOVA followed by Tukey test. Control $>$ ESN+ES $>$ ESN $>$ Denervated $(\mathrm{p}<0.001)$. C) Nerve fibers myelin sheath area $\left(\mu \mathrm{m}^{2}\right)$. Kruskal-Wallis followed by Dunn's method. Control $>$ ESN+ES $>$ ESN $>$ Denervated $(p$ $<0.001)$. D) Nerve fibers myelin sheath thickness $(\mu \mathrm{m})$. Kruskal-Wallis followed by Dunn's method. Control $>$ ESN+ES $>$ ESN $>$ Denervated $(p$ $<0.001)$.

The CTM in control group were characteristic of normal muscle with polygonal fibers, nuclei in peripheral position and little connective tissue. In groups ESN and ESN + ES had similar 
characteristics to the control group, but some slides showed greater amount of connective tissue. Denervated group present muscle fibers with smaller diameter and an increase in the amount of tissue, polymorphism and centralized nuclei showing muscular atrophy (Figure 7).
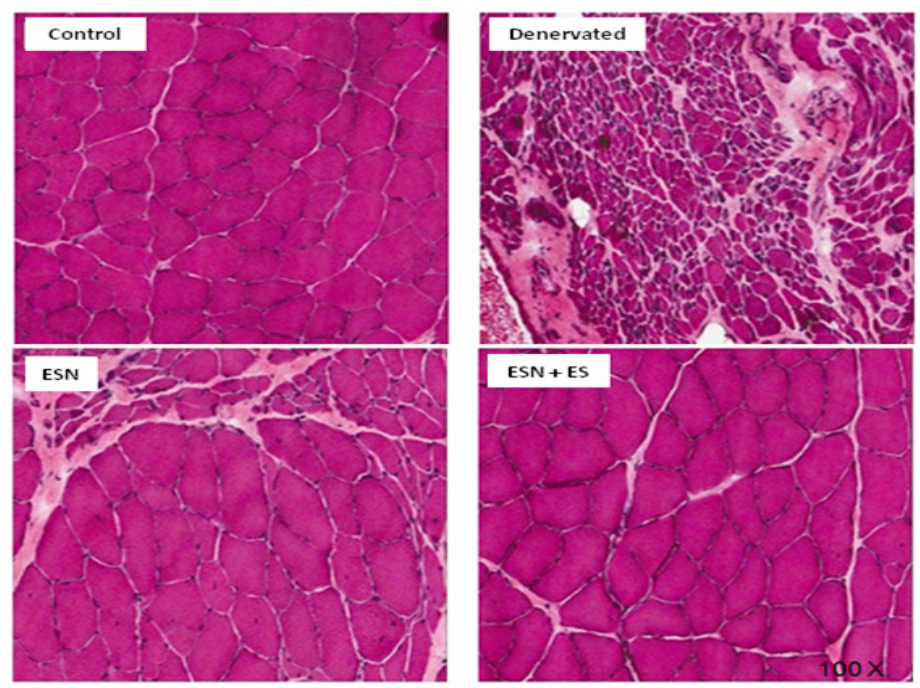

FIGURE 7 - Cross section of the CTM in different groups.

In the cross section of the distal stump of the peroneal nerve (N1) Control group presents great amount of axons, myelin sheath thick and well defined. In groups ESN and ESN + ES observed fewer fibers with thinner myelin sheath of nerve and fibers area smaller relative to control group. We also observed a heterogeneous pattern on the size of nerve fibers in these two experimental groups. In denervated group observed a large amount of connective tissue without presence of nerve fibers (Figure 8).
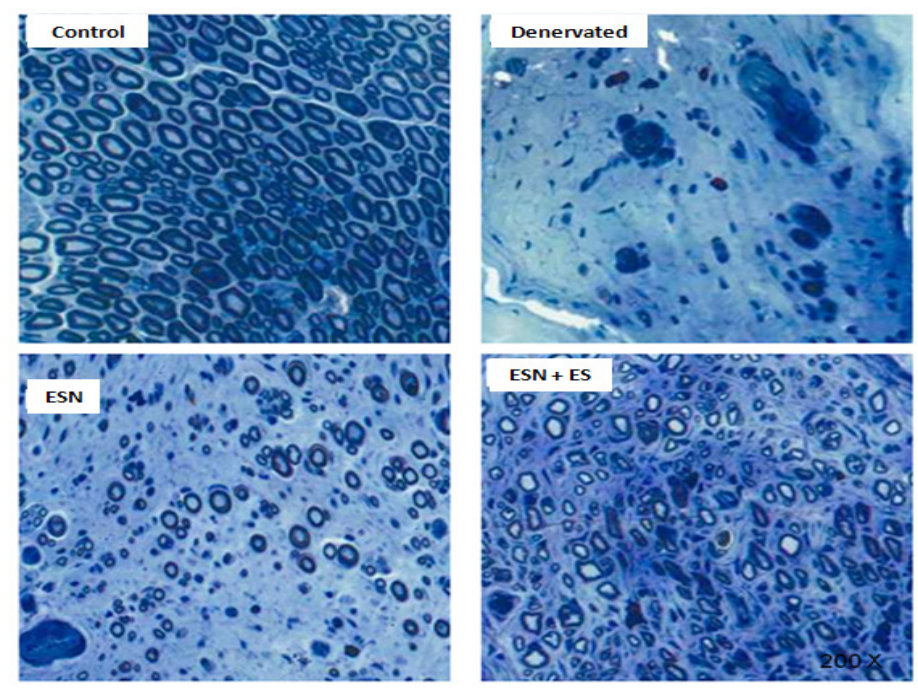

FIGURE 8 - Cross section of the distal stump of the peroneal nerve (N1).

The distal portion of the proximal stump of the peroneal nerve, we observed the presence of neuroma of amputation and discontinuity of the formation of terminal and collateral sprouts (Figure 9A). In the longitudinal section of the neurorrhaphy, we observed nervous sprouting going from the side of the tibial nerve (donor) to the distal stump of the peroneal nerve (receiver). The nerve tissue observed has the same density for the tibial and the peroneal nerves (Figure 9B).

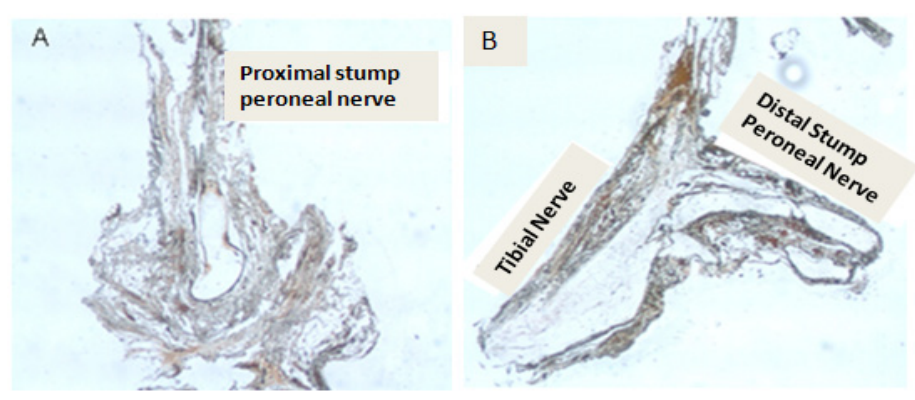

FIGURE 9 - A: Longitudinal section of the proximal stump of the peroneal nerve. B: Longitudinal section of ESN between the distal stump of the peroneal nerve with the lateral surface of the tibial nerve.

\section{Discussion}

Data from this study demonstrate that ES improved function and morphometry for cranial tibial muscle after ESN, also caused nerve regeneration. The WTA showed a vast improvement in receiving ES group reaching Control group similar percentages. After 150 days, only rats subjected to neurorrhaphy with electrical stimulation reached Control group similar levels. In addition, rats subjected to neurorrhaphy with electrical stimulation were the most evolved in relation to PFI, with an improvement of $60.5 \%$. After 150 days ESN+ES group achieved a significant improvement. This may happen because, after the occurrence of muscle reinnervation, electrical stimulation ceases to be a preventive atrophy agent and becomes a muscle training acting directly on the functional improvement of muscle. It is proven that ES in healthy muscles improves it motor activate ${ }^{32,33}$.

A factor that may have contributed to this functional improvement of ESN+ES group was muscle strength, because for this parameter ESN+ES group is highlighted showing greater strength than the others groups and was statistically superior to the ESN group. This finding corroborates with Rutherford and Jones ${ }^{34}$ to suggest that part of the training effect can be achieved by ES in facilitating neural function in a larger number of active motor units and increased pulse rate or a more efficient pattern of recruitment, probably due to a modification of force gradation mechanism, providing improved summation of nerve stimuli.

Cranial tibial muscle mass showed no difference when 
comparing the experimental and normal sides for Control group. In the other groups, the normal side was always higher than the experimental side, but the loss of muscle mass in ESN+ES group $(26.12 \%)$ was lower than the muscle mass loss in ESN group (37.23\%). This has become an important point when we note that a muscle with $10 \%$ more muscle mass, in practical terms, has a higher ability to produce force, it probably will also show a larger transversal section..$^{35}$ During the electrophysiological test, the rats in denervated group that showed no response to electrical stimuli, for just not having the connection between nerve and muscle, were therefore removed from the statistical analysis. The electrophysiological test showed no difference between groups in relation to latency or amplitude. This may indicate equivalence between groups who underwent ESN and Control group in terms of nerve impulse conduction.

The muscle morphometry also demonstrated superiority of ESN+ES group over ESN group. According to the results, ESN+ES group showed greater cross section fibers than ESN group, this shows that ES preserved muscle fibers and further supports functional findings. Looking at the muscle fibers perimeter, area and minimum diameter realize a constant showing Control group higher than others, and ESN+ES group always superior to ESN and denervated groups. This fact shows that ES training was positive for CTM after ESN, as there is a direct relationship between muscle cross-section fibers with muscle strength production. Results found in this study in relation to the nerve N1 segment suggests that there was an acceleration of nerve regeneration. This fact was also observed by Teodori et al. ${ }^{36}$ and Tagami et al. ${ }^{14}$

Our study is unique in that no others researches has utilized the same model to make purposeful comparisons, since most studies using electrical stimulation in denervated muscle spans seven to 52 days of observation and therefore could not possibly asess the functional evolution of animals using histological means in most $\operatorname{cases}^{25,27,28,36,37}$. As our duration of stimulation is relatively high and, the rats would have to undergo several sessions of ES, it was be too risky to anesthetize the rats everytime they were receiving treatment. This would endanger our samples, so we elected to stimulate the rats awake. For this purpose, we developed a method of stimulation that involved capsule restraining of the rats (Figure 3). Electrical stimulation used during this study did not cause any pain or suffering for these rats, because the levels of stimulation were arranged to remain within the motor threshold of the rats and did not reach the pain threshold ${ }^{32}$. The stimulation current parameters were determined based on predetermined criteria. According to $\mathrm{Ward}^{38}$, medium- frequency current with short duration from 2 to $4 \mathrm{~ms}$ were ideal for producing muscle strengthening. The frequency was determined according to the predominant cranial tibial muscle fiber type, as this muscle has a homogeneous mixture of phasic and tonic fibers, previous studies conducted in our laboratory helped us to justify the use $10 \mathrm{~Hz}$ modulation frequency. The current intensity was also determined by previous studies where we found the ideal point for muscular contraction. In our literature review, we found studies using intensity ranges from $1 \mathrm{~mA}$ to $5 \mathrm{~mA}$, however, these studies used anesthetized rats or implanted electrodes ${ }^{24,25,27,28,36}$. For this very reason, we investigated and decided on using $8 \mathrm{~mA}$ as initial intensity in the rats without anesthesia. This intensity was postulated to cause muscle contraction, because there will no muscle training without mechanical work.

\section{Conclusion}

Electrical stimulation was effective in functional muscle maintenance and nerve recovery after end-to-side neurorrhaphy.

\section{References}

1. Lundborg G, Dhalin LB, Danielsen N, Nachemson AK. Tissue specificity in nerve regeneration. Scand J Plast Reconstr Surg. 1986;20(3):279-83.

2. Chem EM, Chem RC. Uso da cola de fibrina na anastomose nervosa: estudo comparativo experimental em ratos. Rev Amrigs. 2004;48(3):171-4.

3. Da Silva CF. Biologia celular e molecular da regeneração nervosa do sistema nervoso periférico. Atual Neurociênc. 1995;1:1-16.

4. Viterbo F, Trindade JC, Hoshino K, Mazzoni Neto A. Lateroterminal neurorrhaphy without removal of the epineural sheath: experimental study in rats. Rev Paul Med. 1992;110(6):267-75.

5. Viterbo F, Trindade JC, Hoshino K, Mazzoni Neto A. End-to-side neurorrhaphy with removal of the epineurial sheath: an experimental study in rats. Plast Reconstr Surg. 1994;94(7):1038-47.

6. Pardini Jr AG, Freitas AD, Plentz EG. Avaliação da sensibilidade após neurorrafia término-lateral de nervos digitais: nota prévia. Rev Bras Ortop. 2005;40(9):543-54.

7. Haninec P, Samal F, Tomás R, Houstava L, Dubovwý P. Direct repair (nerve grafting), neurotization, end-to-side neurorrhaphy in the treatment of brachial plexus injury. J Neurosurg. 2007;106(3):3919 .

8. Lundborg G. A 25-year perspective of peripheral nerve surgery: envolving neuroscientific concepts and clinical significance. J Hand Surg Am. 2000;25(3):391-414.

9. Nemeth PM. Electrical stimulation of denervated muscle prevents decreases in oxidative enzymes. Muscle Nerve. 1982;5(2):134-9.

10. Romão AM, Viterbo F, Stipp E, Garbino JA, Rodrigues JA. Eletroestimulação do músculo tibial cranial após esmagamento do nervo fibular comum: estudo neurofisiológico e morfométrico no rato. Rev Bras Ortop. 2007;42(3):41-6.

11. Souza TD, Del Carlo RJ, Viloria MIV. Eletroterapia no processo de reparação da superfície articular de coelhos. Ciênc Rural. 2001;31(5):819-24.

12. Kotwal A, Scmidt CE. Electrical stimulation alters protein adsorption 
and nerve cell interactions with electrically conducting biomaterials. Biomaterials. 2001;22(10):1055-64.

13. Carvalho DCL, Rosim GC, Gama LOR, Tavares MR, Tribioli RA, Santos IR, Cliquet Júnior A. Tratamentos não farmacológicos na estimulação da osteogênese. Rev Saúde Pública. 2002;36(5):64754.

14. Tagami Y, Kurimoto T, Miyoshi T, Morimoto T, Sawai H, Mimura O. Axonal regeneration induced by repetitive electrical stimulation of crushed optic nerve in adult rats. Jpn J Ophthalmol. 2009;53(3):25766.

15. Ruffin MT 5th, Kningham RB. Anterior knee pain: the challenge of patellofemoral syndrome. Am Fam Physician. 1993;47(1):185-94.

16. Snyder-Mackler L, Delitto A, Stralka SW, Bailey SL. Use of electrical stimulation to enhance recovery of quadríceps femoris muscle force production in patientes following anterior cruciate ligament reconstruction. Phys Ther. 1994;74(10):901-7.

17. Soo CL, Currier DP, Threlkeld AJ. Augmenting voluntary torque of healthy muscle by optimization of electrical stimulation. Phys Ther. 1988;68(3):333-7.

18. McIntyre DL, Robertson DG. Quadriceps muscle activity in women runners with and without patellofemoral pain syndrome. Arch Phys Med Rehabil. 1992;73(1):10-4.

19. Fonseca ST, Cruz ABC, Lima SS, Seixas AFAM. Análise eletromiográfica dos músculos vasto medial oblíquo e vasto lateral em exercícios usados no tratamento da síndrome da dor patelofemoral. Rev Fisioter Univ São Paulo. 2001;8(1):1-10.

20. Wilk KE, Reinold MM. Principles of patellofemoral rehabilitation. Sports Med Arthrosc. 2001;9:325-36.

21. Stiene HA, Brosky T, Reiking MF, Nyland J, Mason MB. A comparison of closed kinetic chain and isokinetic joint isolation xercise in patients with patellofemoral dysfunction. J Orthop Sports Phys Ther. 1996;24(3):136-41.

22. Qin L. Appell HJ, Chan KM, Maffulli N. Electrical stimulation prevents immobilization atrophy in skeletal muscle of rabbits. Arch Phys Med Rehabil. 1997;78(5):512-7.

23. Guirro RRJ, Silva CA, Forti F, Cancelliero KM. Análise do músculo esquelético desnervado tratado com metformina e/ou estimulação elétrica de baixa freqüência. Rev Bras Fisioter. 2004;8(1):21-7.

24. Dow DE, Cederna PS, Hassett CA, Kostrominova TY, Faulkner JA, Dennis RG. Number of contractions to maintain mass and force of denervated rat muscle. Muscle Nerve. 2004;30(1):77-86.

25. Durigan JLQ, Cancelliero KM, Dias CKN, Silva CA, Guirro RRJ, Polacow MLO. Efeitos da estimulação elétrica neiromuscular sobre o membro posterior imobilizado de ratos durante 15 dias: análises metabólicas e morfométricas. Rev Bras Fisioter. 2006;10(3):297302.

26. Russo TL, Peviani SM, Durigan JL, Salvini TF. Electrical stimulation increases matrix metalloproteinase-2 gene expression but does not change its activity in denervated rat muscle. Muscle Nerve. 2008;37(5):593-600.

27. Carvalho LC, Polizello JC, Padula N, Freitas FC, Shimano AC, Mattiello-Sverzut AC. Propriedades mecânicas do gastrocnêmio eletroestimulado pós-imobilização. Acta Ortop Bras. 2009;17(5):269-72.

28. Polônio JT, Mazzer M, Barbieri CH, Mattiello-Sverzut AC. Eletroestimulação seletiva mantem estrutura e função do tibial anterior desnervado de ratos. Acta Ortop Bras. 2010;18(2):85-9.

29. Giovanoli P, Koller R, Meuli-Simmen C, Rab M, Haslik W, Mittlböck M, Meyer VE, Frey M. Functional and morphometric evaluation of end-to-side neurorrhaphy for muscle reinnervation. Plast Reconstr Surg. 2000;106(2):388-92.

30. Isaacs J, Allen D, Chen LE, Nunley J 2nd. Reverse end-to-side neurotization. J Reconstr Microsurg. 2005;21(1):43-8.
31. Bain JR, Mackinnon SE, Hunter DA. Functional evaluation of complete sciatic, peroneal, and posterior tibial nerve lesions in the rat. Plast Reconstr Surg. 1989;83(1):129-36.

32. Maciel FO. Efeitos da corrente russa no ganho de força muscular. Fisioterapia Ser. 2010;5(4):226-9.

33. Ward AR, Shkuratova N. Russian Electrical Stimulation: the early experiments. Phys Ther. 2002;82(10):1019-30.

34. Rutherford OM, Jones DA. The role of learning and coordination in strength training. Eur J Appl Physiol Occup Physiol. 1986;55(1):1005.

35. Henneman E, Olson CB. Relations between structure and function in the design of skeletal muscles. J Neurophysiol. 1965;28:581-98.

36. Teodori RM, Silva AM, Silva MT, Oliveira LS, Polacow ML, Guirro EC. High-voltage electrical stimulation improves nerve regeneration after sciatic crush injury. Rev Bras Fisioter. 2011; 15(4):325-31.

37. Caierão QM, Betini J, Teodori RM, Minamoto VB. O efeito do intervalo da estimulação elétrica no músculo desnervado de rato. Rev Bras Fisioter. 2008;12(2):143-8.

38. Ward AR. Electrical stimulation using kilohertz-frequency alternating current. Phys Ther. 2009;89(2):181-90.

\section{Acknowledgment}

To FAPEAM (Amazonas Research Foundation) for providing Masters Scholarship to Fábio Oliveira Maciel.

\section{Correspondence:}

Fábio Oliveira Maciel

Estrada Coari Mamiá, 305

69460-000 Coari-AM Brasil

Tel.: (55 97)3561-4162

fabiooliveiramaciel@hotmail.com

Received: August 16, 2012

Review: October 17, 2012

Accepted: November 20, 2012

Conflict of interest: none

Financial source: Sao Paulo Research Foundation (FAPESP)

${ }^{1}$ Research performed at Experimental Surgery Laboratory, Department of Surgery and Orthopedics, Botucatu School of Medicine (FMB), State University of Sao Paulo (UNESP), Brazil. 